\title{
MODELAGEM MATEMÁTICA DO CRESCIMENTO DE Lactobacillus viridescens SOB CONDIÇÕES NÃO-ISOTÉRMICAS
}

\author{
A. TREMARIN ${ }^{1}$, J. C. C. P. $\operatorname{COSTA}^{1,2}$, D. A. LONGHI ${ }^{1,3}$, A. P. R. SILVA ${ }^{1}$, C. C. M. PAGANINI ${ }^{1}$, \\ J. B. LAURINDO ${ }^{1}$, G. M. F. ARAGÃO ${ }^{1}$ \\ ${ }^{1}$ Universidade Federal de Santa Catarina, Departamento de Engenharia Química e Engenharia de \\ Alimentos, Florianópolis/SC, Brasil \\ ${ }^{2}$ Universidade Federal de Rondônia, Departamento de Engenharia de Alimentos, Ariquemes/RO, \\ Brasil \\ ${ }^{3}$ Universidade Federal do Paraná, Departamento de Engenharia de Alimentos, Jandaia do Sul/PR, \\ Brasil \\ E-mail para contato: glaucia@enq.ufsc.br
}

\begin{abstract}
RESUMO - As bactérias ácido lácticas (BAL) estão entre os principais grupos de microrganismos responsáveis pela deterioração de produtos cárneos refrigerados, embalados a vácuo e em atmosfera modificada. O crescimento das BAL pode ser predito por modelos matemáticos que descrevem a influência de diferentes fatores ambientais (como condições não-isotérmicas) sobre o crescimento microbiano. O objetivo deste trabalho foi obter um modelo matemático capaz de predizer o crescimento de Lactobacillus viridescens em condições não-isotérmicas de cultivo em meio MRS. As curvas de crescimento foram descritas pelo modelo de Baranyi e Roberts, e a dependência do parâmetro $\mu_{\max }$ com a temperatura foi descrita pelo modelo da raiz quadrada. $\mathrm{O}$ modelo proposto foi validado com dados experimentais de L. viridescens, com a temperatura variando de 5 a $11^{\circ} \mathrm{C}$, e de 6 a $10^{\circ} \mathrm{C}$ a cada $24 \mathrm{~h}$. Os resultados mostraram que foi possível predizer de forma segura, confirmado através dos índices estatísticos, o crescimento de L. viridescens em meio MRS em condições não-isotérmicas.
\end{abstract}

\section{INTRODUÇÃO}

A deterioração de alimentos devido à ação de microrganismos é um problema de grande importância que pode gerar grandes perdas econômicas para as indústrias, tornando fundamental a aplicação de tecnologias para prever a vida útil e obter produtos com maior qualidade (ZueraConsano et al., 2006; Pexara et al., 2002). O comportamento dos microrganismos está intimamente associado com a disponibilidade e qualidade do alimento para o consumo humano, bem como pelas condições de armazenamento (Sperber e Doyle, 2009).

As bactérias ácido lácticas (BAL) pertencem ao grupo das bactérias Gram positivas, não formadoras de esporos, estritamente fermentativas produzindo o ácido láctico como principal produto final (Lyhs e Bjorkroth, 2008). O crescimento incontrolável de algumas espécies resulta em um 


\section{9 a 22 de outubro de 2014 \\ Florianópolis/SC}

impacto negativo como contaminantes, causando a deterioração de produtos embalados a vácuo, em atmosfera modificada, além de produtos cárneos processados armazenados sob temperatura de refrigeração (Françoise, 2010). A deterioração por essas bactérias é principalmente devido à produção de metabólitos, que influenciam na aparência, textura de off-flavors no alimento, causando sabores e odores desagradáveis (Carr et al., 2002; Nychas et al., 2008).

A microflora natural das carnes e produtos cárneos embalados a vácuo ou em atmosfera modificada é composta por Lactobacillus spp.. Entre as espécies predominantes a L. viridescens é considerada uma das espécies mais comuns na deterioração de produtos cárneos, produzindo peróxidos que reagem com os pigmentos da carne, causando o esverdeamento da mesma (Park et al., 2001). O conhecimento e o controle da microbiota presente na matéria-prima durante o processamento cárneo são essenciais para a garantia da qualidade microbiológica e características sensoriais do produto final.

Para avaliar o crescimento microbiano de forma mais rápida e precisa, a microbiologia preditiva vem sendo amplamente utilizada pelo desenvolvimento de modelos matemáticos precisos e versáteis, aptos a descrever a evolução do crescimento microbiano em produtos alimentícios como função de condições ambientais conhecidas ou mensuráveis (Van Impe et al., 2005). Os modelos preditivos têm o objetivo de avaliar o efeito das operações de processamento e das condições de distribuição e armazenamento na segurança e qualidade microbiológica dos alimentos (McMeekin et al., 2002).

Durante o período de estocagem e distribuição dos alimentos a temperatura, na qual estes alimentos estão submetidos, pode sofrer grandes variações. Como a maioria dos modelos preditivos são desenvolvidos para condições de temperatura constante, ocorre a necessidade do desenvolvimento de modelos não-isotérmicos que possam avaliar a influência da flutuação de temperatura ao longo do tempo. Estes modelos são muito válidos para a previsão da vida útil dos alimentos, à medida que eles podem simular as condições reais nas quais os alimentos são submetidos (Koutsoumanis et. al, 2006; Cayré et al., 2003). O objetivo deste trabalho foi obter um modelo matemático capaz de predizer o crescimento de Lactobacillus viridescebs em condições não-isotérmicas de cultivo em meio MRS.

\section{MATERIAL E MÉTODOS}

\subsection{Microrganismo e preparo do inóculo}

A cepa de L. virisdescens (CCT 5843 ATCC 12706, Lote 22.07) foi adquirida na forma liofilizada da coleção de Culturas André Tosello (Fundação Tropical de Culturas André Tosello, Campinas, Brasil). A cepa foi reidratada conforme indicação e cultivada em caldo de Man, Rogosa e Sharpe (MRS) (Difco, Le Pont de Claix, França). Em seguida, foi estocada em microtubos de polipropileno com caldo MRS contendo $20 \%$ de glicerol à temperatura de $-24{ }^{\circ} \mathrm{C}$ para posterior utilização. Para o preparo do inóculo, a cepa congelada a $-24{ }^{\circ} \mathrm{C}$ foi reativada em caldo $\mathrm{MRS}$ a $30{ }^{\circ} \mathrm{C}$ em estufa (Dist, Florianópolis, Brasil), por $18 \mathrm{~h}$. 


\subsection{Condições de crescimento não-isotérmico}

Em estudos anteriores foi avaliada a influência de diferentes temperaturas isotérmicas sobre os parâmetros de crescimento de L. viridescens, obtidos pelo modelo primário de Baranyi e Roberts (Baranyi e Roberts, 1994). Mediante a obtenção destes parâmetros de crescimento foram estudados alguns perfis de temperatura não-isotérmico.

Os experimentos foram realizados em frascos de $500 \mathrm{~mL}$, com volume útil de $320 \mathrm{~mL}$ e com $1 \%(\mathrm{v} / \mathrm{v})$ de inóculo. A concentração inicial dos experimentos foi de aproximadamente $10^{3} \mathrm{UFC} \cdot \mathrm{mL}^{-1}$ e o pH inicial de 6,0 (pH-metro V620, Analion, Ribeirão Preto, Brasil). Os frascos foram incubados em estufa (Dist, Florianópolis, Brasil) em dois perfis de temperatura que variaram entre 5-11 ${ }^{\circ} \mathrm{C}$ e 6$10{ }^{\circ} \mathrm{C}$ a cada $24 \mathrm{~h}$, até que as curvas de crescimento atingissem a fase estacionária. A temperatura mantida dentro das estufas de incubação foi registrada por um datalogger (Testo 174, Lenzkirch, Alemanha) com registro de temperatura e tempo a cada 5 minutos.

\subsection{Construção das curvas de crescimento}

Para a construção das curvas de crescimento utilizou-se o método clássico de contagem de células viáveis para determinar o crescimento de L. viridescens ao longo do tempo até que a mesma atingisse a fase estacionária. No plaqueamento foi utilizado Agar MRS (Difco, Le Pont de Claix, França) com dupla camada, em placas de Petri estéreis descartáveis, incubadas a $30^{\circ} \mathrm{C}$ por $48 \mathrm{~h}$ em estufa (Dist, Florianópolis, Brasil). A contagem foi realizada a partir das placas com 30 a 300 colônias, sendo a contagem expressa em UFC.mL ${ }^{-1}$.

\subsection{Predição do crescimento de $L$. viridescens em condições não-isotérmicas}

Os modelos primário de Baranyi e Roberts (Baranyi e Roberts, 1994), Equações (1) e (2), e secundário de Ratkowsky et al. (1982), Equação (3), foram utilizados para predizer o crescimento microbiano em condições não-isotérmicas Nas Equações (1), (2) e (3), y(t) é o logaritmo natural da concentração celular $(y=\ln (N))$ no tempo t; $Q(t)$ é o estado fisiológico das células no tempo $t$, $\mu_{\max }$ é a velocidade máxima específica de crescimento; e $y_{\max }$ é o logaritmo natural da concentração celular máxima.

$$
\begin{aligned}
& \frac{d y(t)}{d t}=\mu_{\max }\left[\frac{1}{1+e^{-Q(t)}}\right]\left\{1-\exp \left[y(t)-y_{\max }\right]\right\} \\
& \frac{d Q(t)}{d t}=\mu_{\max } \\
& \sqrt{\mu_{\max }}=0,029(T+1,33)
\end{aligned}
$$

As Equações (4) e (5) apresentam as condições iniciais que possibilitam a solução das equações diferenciais (1) e (2), sendo que $y_{0}$ é o valor do logaritmo natural da concentração celular inicial, e $Q_{0}$ 
é o valor do estado fisiológico inicial das células.

$$
\begin{aligned}
& y(0)=y_{0} \\
& Q(0)=Q_{0}
\end{aligned}
$$

\subsection{Validação do modelo não-isotérmico de $L$. viridescens}

A capacidade preditiva dos modelos não-isotérmicos de crescimento foi analisada pela aplicação dos índices estatísticos: coeficiente de determinação $\left(\mathrm{R}^{2}\right)$ (Equação 7), raiz do erro médio quadrático (RMSE) (Equação 8), fator bias (Equação 9) e fator exatidão (Equação 10) (Ross, 1996).

$$
\begin{aligned}
& R^{2}=1-\frac{\sum_{i=1}^{n}\left(\text { valor }_{\text {observao }}-\text { valor }_{\text {predito }}\right)^{2}}{\sum_{i=1}^{n}\left(\text { valor }_{\text {observado }}-\text { média }\right)^{2}} \\
& \operatorname{RMSE}=\sqrt{\frac{R S S}{n-p}}=\sqrt{\frac{\sum\left(\text { valor }_{\text {observado }}-\text { valor }_{\text {predito }}\right)^{2}}{n-p}} \\
& \text { fator bias }=10^{\left(\sum \frac{\log \left(\text { Valor }_{\text {rediio }} / \text { Valor }_{\text {observado }}\right)}{n}\right)}
\end{aligned}
$$

fator exatidão $=10^{\left(\sum \frac{\log \left(\text { Valo }_{\text {predio }} / \text { Valoo }_{\text {observad }}\right) \mid}{n}\right)}$

\section{RESULTADOS E DISCUSSÃO}

A partir dos modelos primários e secundários estabelecidos pelas Equações (1), (2) e (3) foi possível predizer o crescimento de $L$. viridescens sob condições de temperaturas que variam ao longo do tempo dentro da faixa de temperaturas estudadas $\left(4{ }^{\circ} \mathrm{C}\right.$ a $\left.30^{\circ} \mathrm{C}\right)$.

As Figuras 1 e 2 apresentam os resultados da simulação do crescimento microbiano nas condições não-isotérmicas dos perfis $5-11^{\circ} \mathrm{C}$ e $6-10{ }^{\circ} \mathrm{C}$, respectivamente. Para ambos os perfis de temperatura, as curvas de crescimento não-isotérmicas preditas pelos modelos matemáticos superestimaram o crescimento de $L$. viridescens com relação aos dados experimentais, principalmente na fase exponencial de crescimento. 


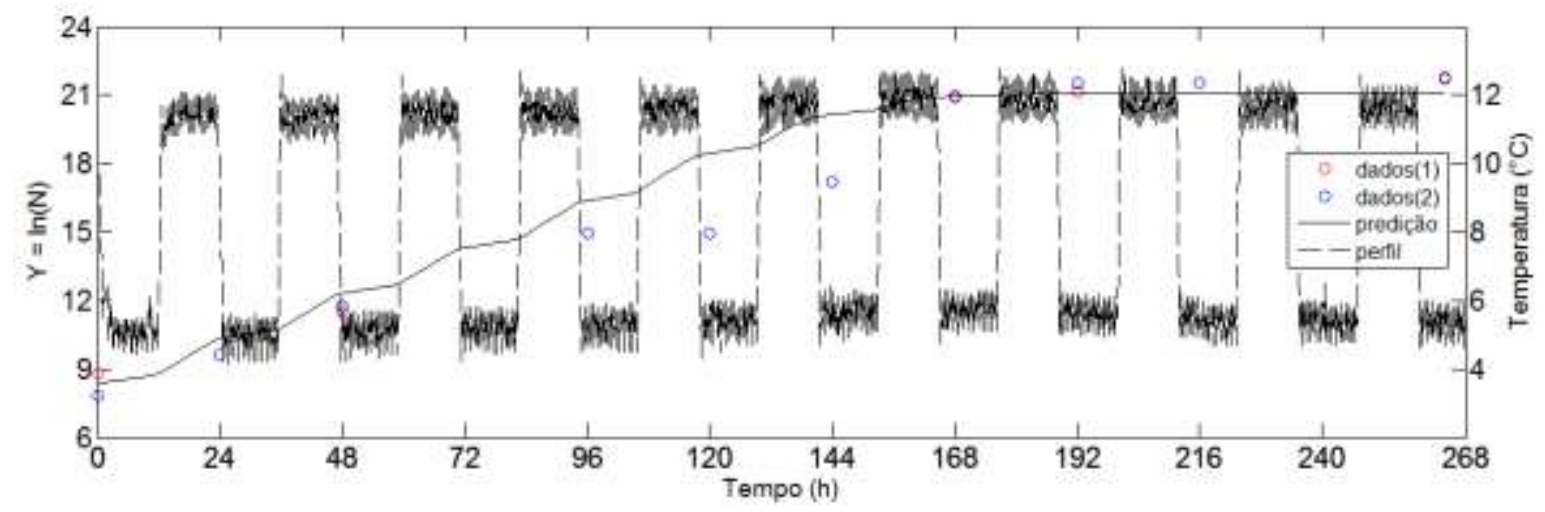

Figura 1 - Curva de crescimento de Lactobacillus viridescens sob condições não-isotérmicas predita pelo modelo matemático (linha contínua) e obtida experimentalmente (pontos) no perfil de temperatura $5-11^{\circ} \mathrm{C}$ (linha tracejada).

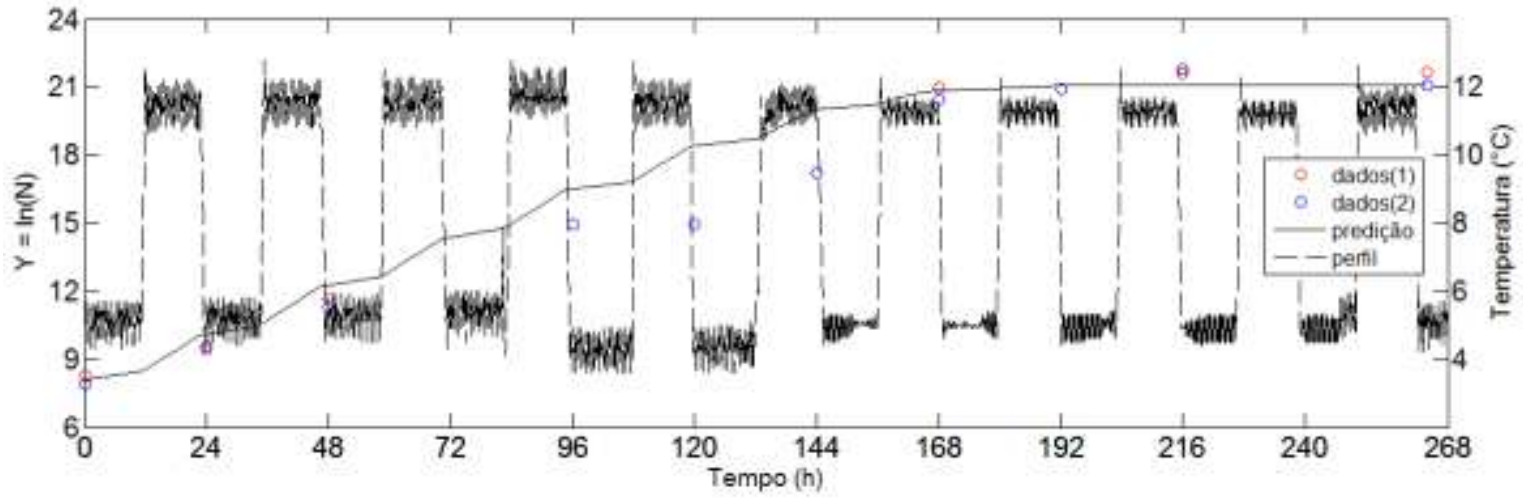

Figura 2 - Curva de crescimento de Lactobacillus viridescens sob condições não-isotérmicas predita pelo modelo matemático (linha contínua) e obtida experimentalmente (pontos) no perfil de temperatura $6-10^{\circ} \mathrm{C}$ (linha tracejada).

Os valores dos índices estatísticos de comparação entre os dados experimentais e a curva de predição do modelo matemático são apresentados na Tabela 1. Os valores encontrados para os índices estatísticos indicam que o modelo avaliado fornece predições seguras do crescimento de L. viridescens em meio de cultivo, pois o valor do fator bias para ambos os perfis de temperatura foi maior que um.

Tabela 1 - Valores dos índices estatísticos $\mathrm{R}^{2}$, RMSE, fator bias e fator exatidão da comparação entre os dados experimentais e a curvas de predições do modelo matemático para os perfis de temperatura $5-11{ }^{\circ} \mathrm{C}$ e $6-10{ }^{\circ} \mathrm{C}$. 


\begin{tabular}{lcccc}
\hline $\begin{array}{l}\text { Perfil de } \\
\text { Temperatura }\end{array}$ & \multicolumn{4}{c}{ Índices Estatísticos } \\
\cline { 2 - 5 } & $\mathbf{R}^{2}$ & RMSE & Fator Bias & Fator Exatidão \\
\hline $5-11^{\circ} \mathrm{C}$ & 0.916 & 1.652 & 1.758 & 2.013 \\
$6-10^{\circ} \mathrm{C}$ & 0.931 & 1.539 & 1.748 & 1.900 \\
\hline
\end{tabular}

As variações bruscas entre as temperaturas dos experimentos (entre 5 e $11{ }^{\circ} \mathrm{C}$, e entre 6 e $10{ }^{\circ} \mathrm{C}$ ) podem ter levado o microrganismo a apresentar fases de adaptação intermediárias, as quais tem sido reportadas na literatura por outros autores (Swinnen et al., 2005; Longhi et al., 2013).

Uma tentativa de predizer o crescimento de $L$. plantarum com variações bruscas na temperatura foi conduzida por Zwietering et al. (1994) usando o modelo de Gompertz. Os autores adicionaram termos empíricos para descrever as fases de adaptação intermediárias apresentadas pelo microrganismo, sendo que a modificação no modelo aumentou a capacidade preditiva em 73\% dos casos. Entretanto, nos casos em que a temperatura do experimento foi próxima da temperatura mínima de crescimento do microrganismo (como é o caso do presente estudo), as predições com o modelo modificado não foram satisfatórias. Desta forma, a construção de modelos matemáticos que consigam predizer o crescimento microbiano para mudanças bruscas de temperatura próximas da temperatura mínima de crescimento continuam sendo um desafio para os pesquisadores.

Alguns trabalhos na linteratura também tem apresentado problemas de predição ao avaliar o crescimento de outros microrganismos com variação brusca de temperatura próximo da temperatura mínima de crescimento, por exemplo, o crescimento de Pseudomonas spp. em peixe refrigerado entre 5 e $15^{\circ} \mathrm{C}$ (Corradini e Peleg, 2005), e o crescimento de Listeria monocytogenes em leite pasteurizado entre 4 e $12{ }^{\circ} \mathrm{C}$, e entre -2 e $6{ }^{\circ} \mathrm{C}$ (Xanthiakos et al., 2006).

\section{CONCLUSÃO}

O modelo matemático proposto foi validado com os dados experimentais de L. viridescens para os perfis de variação de temperatura entre 5 e $11^{\circ} \mathrm{C}$, e entre 6 e $10^{\circ} \mathrm{C}$ a cada $24 \mathrm{~h}$. Os resultados mostraram que foi possível predizer de forma segura (fator bias maior que um) o crescimento de $L$. viridescens em meio MRS em condições não-isotérmicas.

\section{REFERENCIAS}

BARANYI, J.; ROBERTS, T. A. A dynamic approach to predicting bacterial growth in food. International Jounal of Food Microbiology, v. 23, p. 277-294, 1994.

CARR, F. J.; CHILL, D.; MAIDA, N. The lactic bacteria a literature survey. Critical Reviews in Microbiology, v. 28, n. 4, p. 281-370, 2002. 
CAYRÉ, M. E.; VIGNOLO, G.; GARRO, O. Modeling lactic acid bacteria growth in vacuumpackaged cooked meat emulsion stored at three temperatures. Food Microbiology, v. 20, p. 561-566, 2003.

CORRADINI, M.; PELEG, M. Estimating non-isothermal bacterial growth in foods from isothermal experimental data. Journal of Applied Microbiology, v. 99, p. 187-200, 2005.

FRANÇOISE, L. Occurrence and role of lactic acid bacteria in seafood products. Food Microbiology, v. 27, p. 698-709, 2010.

KOUTSOUMANIS, K. P.; STAMATIOU, A.; SKANDAMIS, P.; NYCHAS, G. J. Development of a microbial for the combined effect of temperature and $\mathrm{pH}$ on spoilage of ground meat and validation of the model under dynamic temperature conditions. Applied and Environmental Microbiology, v. 71, p. 124-134, 2006.

LYHS, U.; BJORKROHT. Lactobacillus sakei curvatus is the prevailing lactic acid bacterium group in spoiled maatjes herring. Food Microbiology, v. 25, p. 529-533, 2008.

LONGHI, D. A.; DALCANTON, F.; ARAGÃO, G. M. F.; CARCIOFI, B. A. M.; LAURINDO, J. B. Assessing the prediction ability of different mathematical models for the growth of Lactobacillus plantarum under non-isothermal conditions. Journal of Theoretical Biology, v. 335, p. 88-96, 2013.

McMEEKIN, T. A.; OLLEY, J. N.; RATKOSWSKY, D. A.; ROSS, T. Predictive microbiology: towards the interface and beyond. International Journal of Food Microbiology, v. 73, p. 395-407, 2002.

NYCHAS, G. J. E.; SKANDAMIS, P. N.; TASSOU, C. C.; KOUTSOUMANIS, K. P. Meat spoilage during distribution. Meat Science, v. 78, p. 77-89, 2008.

PARK, S. W.; SOHN, K. H.; SHIN, J. H.; LEE, H. J. High hydrostatic pressure inactivation of Lactobacillus viridescens and its effects on ultrastructure of cells. International Journal of Food Science and Technology, v. 36, p. 775-781, 2001.

PEXARA, E. S.; METAXPOULOS, J.; DROSINOS, E. H. Evaluation of shelf life of cured, cooked, sliced turkey fillets and cooked pork sausages - piroski - stored under vacuum and modified atmosphere at +4 and $+10^{\circ}$ C. Meat Science, v. 62, p. 33-43, 2002.

RATKOWSKY, D.; OLLEY, J.; MCMEEKIN, T.; BALL, A. Relationship between temperature and growth-rate of bacterial cultures. Journal of Bacteriology, v. 149, p. 1-5, 1982.

ROSS, T. Indices for performance evaluation of predictive models in food microbiology. Journal of Applied Bacteriology, v. 81, p. 501-508, 1996.

SPERBER, W. H.; DOYLE, M. P. Compendium of the microbiological spoilage of foods an beverages. London: Springer, 2009.

SWINNEN, I. A. M.; BERNAERTS, K.; GYSEMANS, K.; VANIMPE, J. F. Quantifying microbial lag phenomena due to a sudden rise in temperature: a systematic macroscopic study. International Journal of Food Microbiology, v. 100, p. 85-96, 2005.

VAN IMPE, J. F.; POSCHET, F.; GEERAERD, A. H.; VEREECKEN, K. M. Towards a novel class 
of predictive microbial growth models. International Journal of Food Microbiology, v. 100, p. 97$105,2005$.

XANTHIAKOS, K.; SIMOS, D.; ANGELIDIS, A.; NYCHAS, G.; KOUTSOUMANIS, K. Dynamic modeling of Listeria monocytogenes growth in pasteurized milk Journal of Applied Microbiology, $\mathrm{v}$. 100, p. 1289-1298, 2006.

ZWIETERING, M. H.; WIT, J. C.; CUPPERS, H. G. A. M.; VAN'T RIET, K. Modeling of Bacterial Growth with Shifts in Temperature. Applied and Environmental Microbiology, v. 60, n. 1, p. 204-213, 1994.

ZURERA-CONSANO, G.; GARCÍA-GIMENO, R. M.; RODÍGUEZ-PÉREZ, M. R.; HERVÁSMARTÍNES, C. Validation an artificial neural network model of Leuconostoc mesenteroides in vacuum packaged sliced cooked meat products for shelf life estimation. Food Control, v. 17, p. 429438, 2006. 